\title{
Prevent or Cure? - A New Philosophy of Health Care
}

\author{
Izabela Nawrolska \\ Department of Finance, Faculty of Economics and Management, University of Szczecin, Poland
}

Copyright $(\mathcal{C} 2015$ by authors, all rights reserved. Authors agree that this article remains permanently open access under the terms of the Creative Commons Attribution License 4.0 International License

\begin{abstract}
Health care systems evolve at the same time in many different ways: in area of developing technologies, the development of the medical knowledge, because of demographical changes and particularly - aging of the society. This induces modifications of the priorities of the health policy, new methods of organization and more complex funding mechanisms. Individual components of the health care system: illness prevention and health promotion , basic health care, hospital care have different contribution into the health care systems of different countries. The worlds growing awareness that for keeping and improving the population health the governments must create effective and efficient health system leads to the effective illness prevention. It shouldn't be expected that the health effects and economic efficiency of the health care system will improve, without appropriate expenditures on actions which delay or prevent illness, and also allow early diagnosis and effective (usually cheaper) treatment. In the first part of the paper there will be discussed issues connected with modern health conceptions which create the fundaments of the approach to the illness prevention. Health care is the specific public goods. This induces the choice of criteria, used by policy makers, to allocate public sources. In the second part the crucial significance is to specify the determinant of the changes of the health benefits structures financed from the public means. The last part of this elaboration, based on gathered empirical data, will discussed experiences of the selected European countries on prevention of the selected illnesses, indicating the links between expenditures and the effects of the prevention activities.
\end{abstract}

Keywords Health Care Systems, Prevention Activities, Health Prevention Finance, Public Finance

\section{Introduction}

Health care systems undergo evolution in many areas at the same time - in the aspect of progressing technology, increasing medical knowledge, demographic changes, in particular, society's ageing, changing morbidity and modified priorities of the health policy, new organization methods and more complex financing mechanisms. Individual components of the health care system: disease prevention and health promotion, primary health care, hospital treatment have a different share in health care in various countries. European health care systems are widely appreciated mainly due to the fact that they ensure the access to treatment for the users of the system for a reasonable price. However, it is increasingly understood that in order to maintain and improve population health, governments have to create an efficient health care system leading to effective disease prevention and health promotion. Without appropriate expenditures on actions which will delay the occurrence of diseases or their prevention and will also enable early diagnosis and effective (often cheaper) treatment, no significant improvement of health results or improvement in economic effectiveness can be expected.

\section{Contemporary Concepts of Health and Disease}

Until the first half of the 20th century, the biomedical approach was the dominant approach to the issues of health and disease in the European culture. The focus was on disease understood as a pathological lesion in the body contributing to reduced fitness or shortened life spans [1]. This approach resulted from the perception of acute diseases (including contagious diseases) as a dominant medical problem. Changes in the picture of diseases observed in industrialized countries in the second half of the 20th century turned out to be the reason for modifying the approach to health. Chronic diseases, also called diseases of civilization, became the leading problem instead of contagious diseases. Apart from indisputable evidence of the large number and diversity of factors influencing the health, it is now thought that changes in the approach to health were society's response to unsatisfactory results, unacceptable methods and negative effects of health care functioning [2]. The development of medicine over the past two decades means mostly new diagnostic and therapeutic possibilities as well as new areas of scientific thinking, such as health education, preventive treatment and health promotion, public health. More and more scientists and researchers are in favour of a 
health concept which would treat health in a holistic and complementary manner, i.e. in favour of creating definitions which do not only deal with the essence of the issue but also provide a broader context of its meaning in the form of a paradigm. The process of socio-ecological model has begun to displace the so called biomedical model when considering health problems. At present, the focus is not on disease but on health [3] Changes in the picture of diseases involving transition from acute to chronic diseases made it necessary to replace medical interventionism which predominated in the biomedical model with observations of population health. Moreover, it was proved that the exclusive use of corrective actions is not sufficient to fight chronic diseases effectively, and, as a result, more and more attention has been attached to preventive treatment. The subject of actions undertaken in the area of health is not a patient any more, but a healthy person, who has to take responsibility - in a much broader scope than so far - for his health condition. Being aware of the influence of lifestyle on health condition of a population makes it clear that the most significant organizational form in health care system are not medical institutions but the society, in which a person functions every day and from which an individual acquires attitudes, health related behaviours and values that are attributed to health.

In the light of the presented changes in the approach to health, public health actions gain particular importance. All countries deal with chronic diseases. These are diseases largely conditioned by environmental factors or lifestyle. Thus, challenges faced by public health and, thus, broadly understood health care, are similar and also the necessity of taking decisive actions in the public health area is common. There are, however, various approaches to providing health care and their special character includes mutual relationships between private and public health care and the methods of financing it - from direct payments, insurance or taxes. Political and economic conditions are also of some importance here. It all, together with conditions for the development of a public health policy, means that individual national solutions may be characterised by various organizational structures of health care, including promotional and preventive actions to a various degree.

It is even hard to acknowledge that such concepts as prevention, health promotion or public health care are considered equal in every country. It makes it difficult to directly compare the applied solutions in the scope of disease prevention. The efforts of international and supranational organizations resulted in the fact that prevention and health promotion have become considered more important, demonstrating the tendency of national health policies to converge which is reflected in most significant strategic documents and recommendations of European and international organizations, such as WHO, OECD, the European Commission and the European Council.

Focusing on prevention and health promotion in documents and strategies of individual countries is undoubtedly a positive direction of changes, however, it does not guarantee the realization of the assumptions as these will be dependent on a range of factors - institutional, organizational and mainly financial ones. Individual European Union countries are characterized by different levels of health care financing and the related problems. Depending on the stage of socio-economic development of the country, the significance of particular factors that cause tensions in the system of health care financing, is different. A demographic factor constitutes the biggest problem for the highly-developed countries of Western Europe, whereas new countries of the Union, such as Poland, so far have been dominated by the effects of a technological factor influence. The reaction of politicians on the emerging tensions involves the continuous process of reforms and their considerable part is concentrated on the aspects of health care financing.

When comparing health care systems, one thing is certain irrespective of the country under consideration: health needs of the society are always much greater than the capabilities of the country to finance them. The issues related to the questions of where to look for savings, where the sources should be definitely increased or whether all the sources are appropriately allocated have always been controversial.

\section{Determinants of Changes in the Structure of Health Services}

Over the years, the improving health of society was treated as a result of social and economic progress. At present it is shown that health is not only the key indicator of success but also the key determinant and source of economic growth. In accordance with the approach proposed by Bloom [4], in countries with high income, health may contribute to economic results (both as regards individuals and the national level) mostly by means of higher productivity, higher supply of labour force, education (understood as greater skills as a result of education and training), capital generation (more savings available for investing in physical and intellectual capital). Thus, health is, on the one hand, a factor of economic growth and, on the other hand, the economic growth is a significant factor contributing to higher standards of living. Good living conditions (hygiene, food, accommodation) resulting from general prosperity have a direct influence on increasing the body's immunity, contribute to lower incidence of diseases, thus having a positive influence on the population's health [5].

Discussions are being held practically in all countries on how to meet the growing needs of societies in the area of health care. Per capita expenses in OECD countries have increased by $70 \%$ in real terms since the beginning of the 1990s. Optimization of these expenses is one of the main challenges faced by political decision makers in developed countries. However, full understanding of processes determining an increase in expenses on health is a necessary stage and the starting point for conducting reforms in this area. Three key factors influencing the growing demand for health services can be distinguished: the demographic factor, the income factor and the technological factor (Diagram 3). 


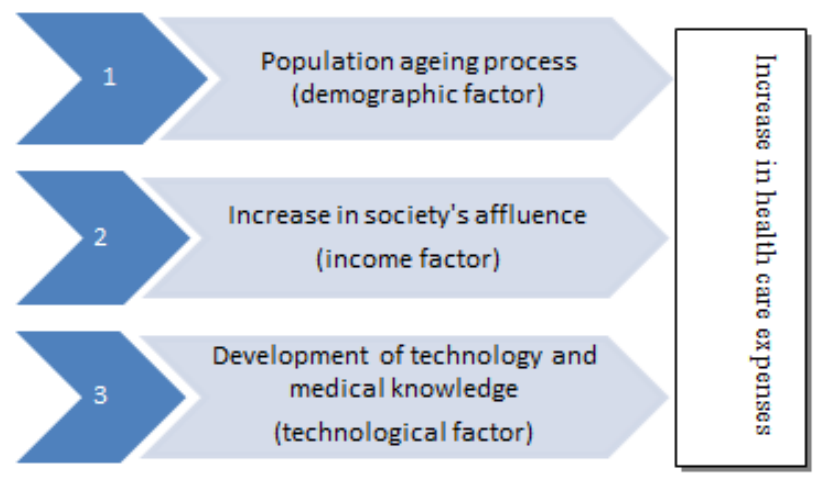

Source: own work

Diagram 3. Factors exerting pressure on the increase in health care expenses Source: own work

The mechanism of action of the aforementioned factors is similar in all of these countries. Their impact is different, however.

\section{Demographic Factor}

The influence of demographic changes on the increase in health expenditures is a complex problem. Europe, also including Poland, is ageing at an alarming rate. In the next decades, above-average dynamics of population ageing will take place. Society's age structure which will occur in European countries will bring serious economic and social consequences. It will give rise to a financial pressure on the health care system due to a higher probability of using health services by older persons for whom the average cost of treating one patient is higher. In accordance with available long-term forecasts, Poland's population will grow old very strongly in the coming decades. The number of people under 65 will increase from 5.1 million in $2010(13 \%$ of the population) to 11.3 million in 2060 (over $34 \%$ of the population). The percentage of the working-age population (20-64 years of age) will decrease from $65 \%$ in 2010 to $49 \%$ in 2060. It results from the analysis of expenses of the National Health Fund (NFZ), the main payer in the Polish health care system, that the average annual expenses per person under 65 years of age amounted to PLN 1.2 thousand and PLN 3.4 thousand in the group of persons over 65 years old. Thus, it can be concluded that, together with a change in the age structure of Poles, it will be necessary to significantly increase health care expenses to keep services at the current level. The population ageing process in Poland will progress much more quickly than in other EU countries. This means that the demand for relatively more expensive medical services will belong to the highest in Europe.

\section{Income Factor}

There exists an important relationship between the economic development level and the amount of health care expenses in a given country: in more affluent countries (higher per capita GDP) more money is spent on health care (higher expenses on per capita health care). What is more, it results from research that expenses on health grow faster than the income. Thus, from the economic point of view, health is a luxury - together with an increase in affluence people are ready to use a growing part of their income for this purpose. A similar relationship can be also observed in Poland. In the years 1990-2010, the annual GDP in current prices grew 23 times in Poland. During the same period, nominal expenses on health increased 34 times. As a result, the health expenses to Poland's GDP ratio increased from $4.8 \%$ to $7 \%$ in the years $1990-2010$.

\section{Technological Factor}

The development of technology and medical knowledge is the third significant factor resulting in an increase in demand for medical services. Two key mechanisms of the influence of the technological effect on health care expenses are pinpointed in the literature:

- reduction of unit costs of treating known diseases,

- extended scope of treated diseases.

Theoretically, the first mechanism acts towards the reduction of costs in the health care system. In practice, due to insufficient funds for the health needs in the majority of health care systems (also including Poland), savings obtained from the reduction of unit costs are used towards increasing the availability of individual treatments.

The second mechanism exerts pressure on the increase in expenses as it generates demand in new, previously non-existing areas. As a result, the net influence of technological progress on health care expenses is positive. This is confirmed by empirical research. Despite the fact that the measurement of costs connected with medical technology is difficult due to limitations of access to appropriate data, a lot of studies show that, historically, the development of medical technology is responsible for a large part of the increase in health care expenses. Studies of the European Commission provide a range for the importance of technology in the increase in expenses on health care in developed countries - from $27 \%$ to as many as $75 \%$.

In accordance with the European Commission's forecasts, the factors described above (the demographic, income and technological ones) will lead to an increase in demand for financial health services by $2.6 \%$ of the GDP by 2060 . It is worth emphasizing that this will be one of the greatest relative increases (in relation to the GDP) among all EU countries. In the European Commission's opinion, the demographic factor will be responsible for approx. $70 \%$ of the increase in demand in Poland and extra-demographic factors, i.e. increase in affluence and development of technology will be responsible for only $30 \%$ of the increase (Graph 1). 


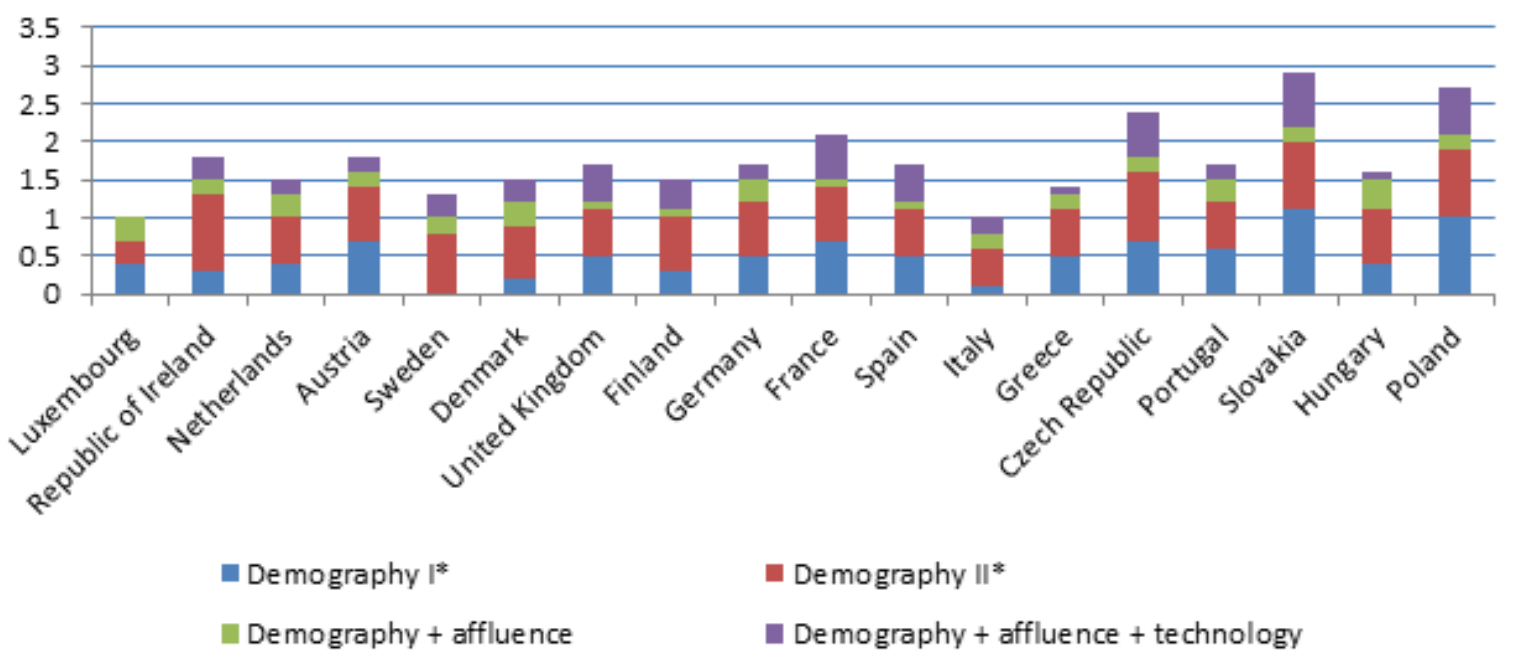

*scenario of population ageing in good health

**The difference between the ageing effect in good and bad health - the sum of the blue and red columns shows the combined effect of ageing in bad health. Source: Own work on the basis of European Commission, The 2012 Ageing Report ; the countries are arranged in accordance with the decreasing GDP per person (USD PPP) in a given country in 2008

Graph 1. Increase in demand for health care financed from public funds in the years 2010-2060

The described factors will exert a growing pressure on increasing health care expenses. At present, in Poland, just like in a vast majority of European countries, public funds are the main source of financing expense connected with health care. The share of public funds in total health care expenses in Poland amounts to approx. $71-72 \%$. Thus, less than $30 \%$ of total health care expenses are covered from private sources and this share has not changed significantly over the past decades

In the majority of European countries, the source of financing public health care expenses are general taxes (the so-called Beveridge system) or para-taxes which usually function in the form of mandatory social insurance (the so-called Bismarck system). In each model, an increase in public health care expenses must be accompanied by:

- deterioration of the balance of the public finance sector or

- increase in the tax burden - taxes or mandatory health insurance premiums or

- limitation of other public expenses.

Of course, any combinations of the aforementioned effects are possible. However, considering the current economic and fiscal conditions, scenarios of a significant increase in public expenses on health care within the next few years do not seem very likely.

Also in Poland, further fiscal consolidation cannot be avoided in the coming years. The national public debt to the GDP ratio was $52.8 \%$ at the end of 2010 . At the same time, the first prudential threshold indicted in the Public Finance Act was exceeded (50\% of the GDP). Additionally, in 2011, the national public debt to the GDP ratio came close to the next prudential threshold (55\% of the GDP). At the same time it should be remembered that the so-called excessive deficit procedure has been currently imposed on Poland by the European Council. This decision is a result of exceeding by Poland the designated threshold of a 3\% deficit in the government and local government sector in relation to the GDP. In connection with this procedure, Poland must reduce its deficit to a level below the indicated threshold during the next years.

The question how to cure the best considering the fact that resources are limited is still applicable and it is gaining a status of a health care dilemma. This dilemma is growing due to the determinants specified above and also due to society's growing awareness and its demands that effective technologies should be used and decisions made should be justified.

The structure of health services reflects the shape of the health policy and its directions, defined priorities, which with limited financial resources on the one hand and, on the other hand, with unlimited health needs - are the condition for making decisions on fund allocation. Analyses of this structure can be performed using various cross sections. The preparation of National Health Accounts according to unchanged rules, in accordance with the adopted international methodology allow for observing the dynamic of the values assigned to the individual categories of expenses and changes occurring in their structure. Thus, considering the intended functional use of expenses incurred, it can be concluded that in recent year the vast majority of expenses in Poland (90\%) are expenses on individual health care including medical services, rehabilitation services, long-term nursing care, auxiliary services as well as medication and other medical products. Other expenses were used towards actions connected with preventive treatment and public health, administrative functions and investments. 


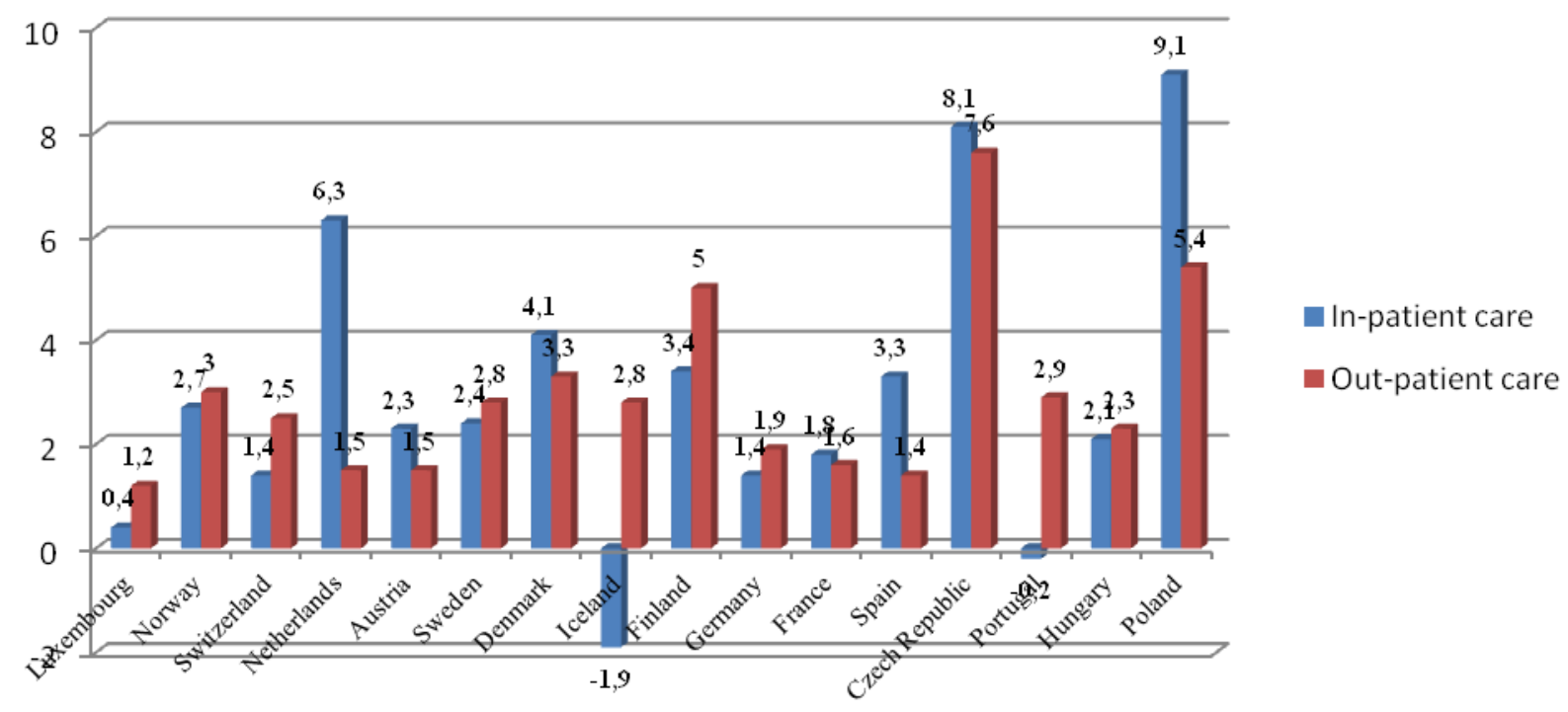

Source: prepared by the author on the basis of Health Data OECD 2011, the order of countries is sorted according to the decreasing GDP per person (USD PPP) in a given country in 2008

Graph 2. Annual average growth in inpatient and outpatient care expenditure per capita, in real terms, 2000 to 2009

The share of individual types of services mostly depends on institutional solutions in the individual health care systems. Hospital care, which is the most cost-consuming and outpatient care are usually the dominant position.

The increase in expenditures on particular areas of health care reflects in part the stage of development of health care systems. Some countries introduce solutions that enable them to reduce the role of hospital care, which is more cost-intensive, in favour of out-patient care, increasing the number of one-day surgeries or care at home. However, this change may also demonstrate regulatory issues. OECD analyses indicate that such countries as Poland or Czech Republic that wish to develop their health care systems, among others through investments, demonstrate a rapid increase in spending on hospital care and it is the main growth factor of these expenditures. However, this growth may also indicate, which is ignored in international analyses, the lack of financial balance in health care systems, mounting debt of health care units or simply continuation of the use of allocation models that have been used for years. In the last decade in Poland, the increase in expenditure on hospital care per capita was the greatest among the analysed countries (graph 2).

One of significant differences between Poland and Western European countries which can be assessed from the point of view of directions of the health policy is the level of expenses incurred on nursing and care services. In Poland, such expenses are marginal (their share in the total expenses is approx. 2\%), while in EU countries where the society ageing process started earlier, this share is approx. $10 \%$ of the total current expenses. In some cases, this share is much higher For instance, Netherlands, Norway or Denmark allocated on them $1 / 4$ of their total expenses in 2009 [6].

In a vast majority of cases, the continuation of the use of allocation models which have been used for years predominates without attempts at defining health benefits. At the same time, contemporary dynamic economic and social changes bring, apart from new possibilities, also hazards to the health of many groups of people and the allocation of funds based on the historical method proves to be insufficient to improve the population's state of health. The view that an effective solution involves increases the share of preventive treatment at the expense of the share of hospital treatment. The dynamics of chronic diseases which occur more and more frequently at a young age are characterised by high direct and indirect costs and show the necessity of increasing expenditures and of more effective implementation of programs in the area of health prevention.

\section{The Place of Preventive Treatment of Diseases in Health Care Systems Financed from Public Funds}

As a result of the complexity of the problem of financing disease prevention, the lack of sufficient, uniform and comparable data, the assessment of the actual financing level still constitutes an enormous gap in research pertaining to both individual countries and international comparisons. Attention should be paid to the lack of possibility of distinguishing expenditures on disease prevention - some actions connected with disease prevention are sometimes treated as medical interventions and their identification in the financing system in individual countries is difficult and often impossible. Despite these difficulties, an attempt at comparing the amount of expenditures connected with disease prevention in European countries over the past 10 years, it can unambiguously concluded that prevention and public health are not the main direction of public fund allocation in health care systems. Their share in total public 
expenses on health care ranged from $0.6 \%$ in Italy to $3.7 \%$ in Finland [7]. Thus, the differences occurring in individual countries are considerable.

The analyses of the European Commission also indicate a small share of expenditures on prevention among other components of expenses on health care, both in 'old' countries of the EU (EU 15) and in new EU countries (EU
12). Wages constitute the greatest part in general expenses, followed by pharmaceutical expenditure and capital investment (chart 3) [8].

Graph 4 presents per capita public expenses on prevention and public health in selected European countries. Due to the greatest availability of information, data in the drawing pertain to the year 2010 .

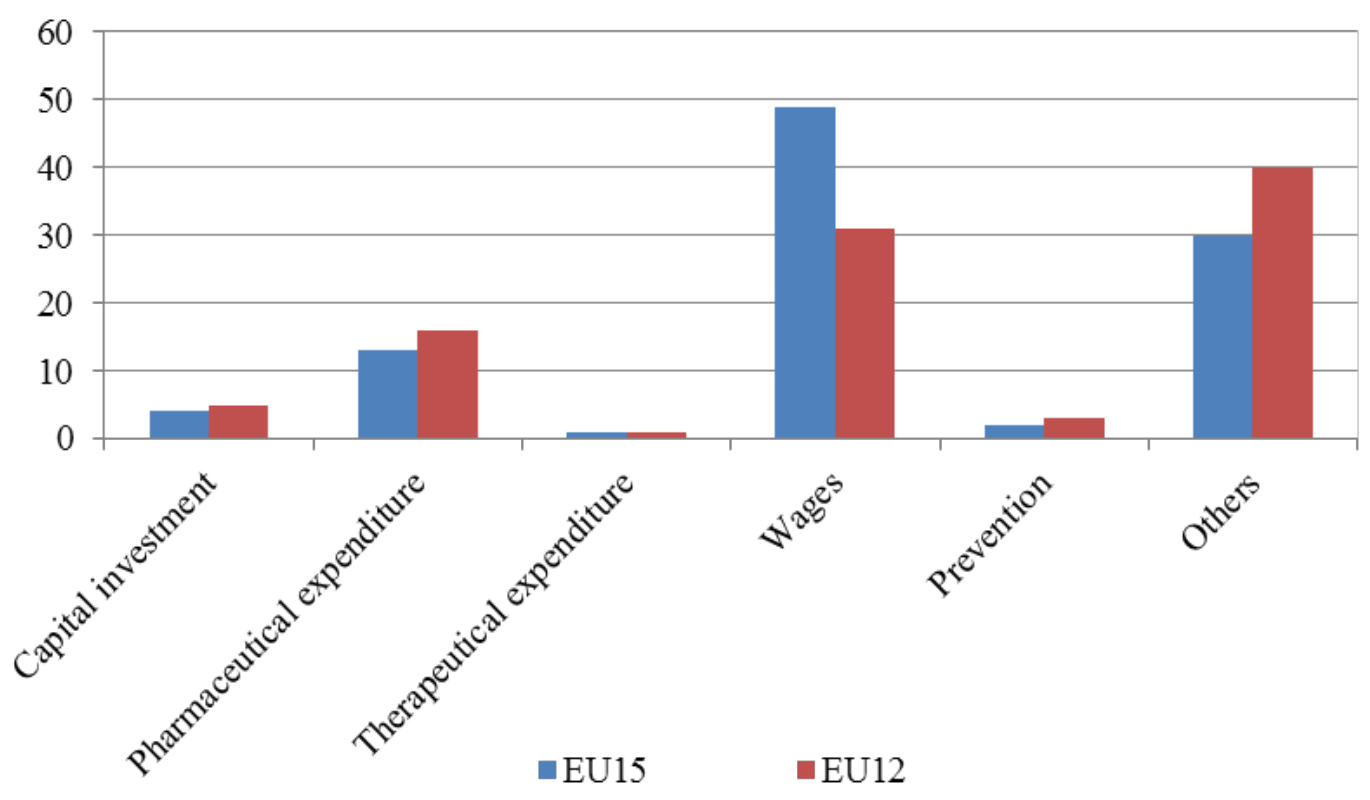

Source: European Commission, The 2012 Ageing Report.

Graph 3. 10-year average shares of expenditure components in total care spending (1999-2008), in\% in EU15 and EU12

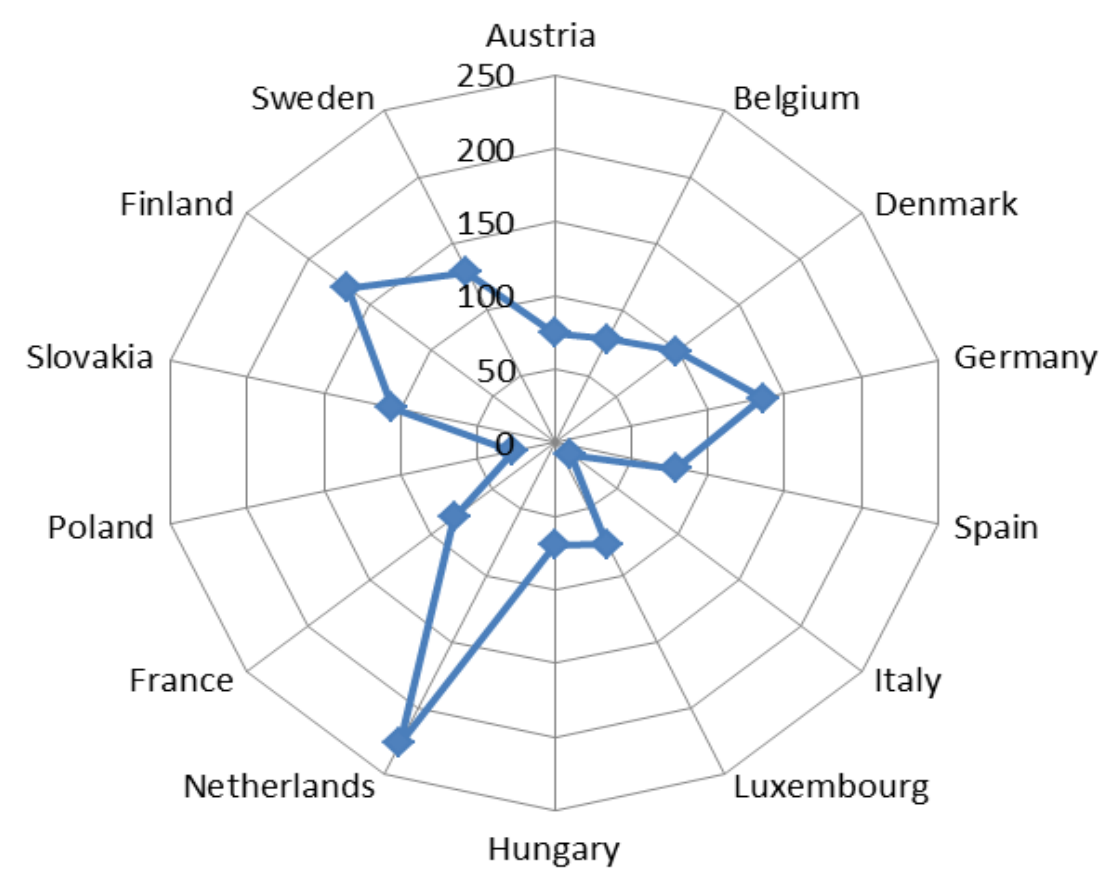

Source: prepared by the author on the basis of Health Data OECD 2012.

Graph 4. Per capita public expenses on prevention and public health in selected European countries in 2010 (in USD according to PPP). 
Considering the typologies of health care systems from the most classical one in which the sources of financing are the criterion to the division of systems according to reforms conducted which concern these sources, no regularities can be identified in a greater or smaller use of public funds towards preventive actions. Countries which have health care systems based on the Bismarck model (insurance models), such as Austria, Germany, France use various amounts of funds for health and are, at the same time, countries with a high income. Similarly, Denmark, Sweden and Finland which have systems based on the Beveridge model where financing from general taxes received by the state budget is the basis show various levels of expenditures, similar in Sweden and Finland but lower in Denmark. Noticeable differences can be also observed between Spain and Italy, despite the fact that they are both described as countries with models going in the direction of full budget models. The division of health care systems according to institutional similarities does not account for differences in the level of public expenses on prevention and public health. It seems that the most important, and possibly the only determinant, is the total amount of health care expenses, which is strongly correlated with the GDP, although also here some exceptions occur, e.g. in Austria.

Poland spends the least from among the selected countries in the per capita approach. As a result, it is even more important to assess actions taken in Poland in a more accurate manner.

The Polish health care system has gone through two serious reforms over the past two decades [9]. In the year 1999, budget funding was replaced by insurance and budget funding with a significant predominance of the insurance segment, new insurance institutions were introduced (health boards, association of health boards, health insurance supervision office) and they operated until 31 March 2003 when the health board system was replaced by the National Health Fund (NFZ). Both for former health boards and the currently functioning National Health Fund, the basic source of revenues of the health care system and also the source of financing public health services is the insurance premium. The state budget mostly collected from general taxes is the second largest source of funds. Also, budgets of local government units whose income mostly comes from the specified share in general taxes, from own payments and taxes and the state's subsidies and grants.

Main entities whose actions are of key importance in the area of prevention - planning and financing of preventive health programs are the Ministry of Health, the National Health Fund and the local government which has taken over the responsibility for the condition of the local community's health.

The share of expenses of the state budget - the primary payer implementing health programs, including preventive health programmes - decreased systematically since 2009 . Only in 2010, a 2\% increase was observed. In the structure of expenses of the local government on health care, health policy programmes constituted a small part in the years 2006-2012. A systematic increase from the level of PLN 51.8 million in 2006 to PLN 82.5 million in 2010 , but this is a very small percentage of local government units expenses in health care expenses. The level of financing preventive health programs in general expenses of the National Health Fund is only approx. $0.20-0.30 \%$ (Table 1).

In the context of the systematic increase in health care expenses in recent years, it must be concluded that in Poland preventive functions are neglected in the health care system, despite the evidence showing the rationality of actions in the area of public health and against postulates of $\mathrm{WHO}$ and the European Commission. Unfortunately, difficult to notice ongoing results of preventive actions often result in marginalization of these problems. A more serious social problem can always occur. Hence, preventive programs require more efficient actions so as to ensure a sufficient level of their implementation with stable financing.

Table 1. Expenses from the state budget, the National Health Fund, local government units on the implementation on health policy programs* in the years 2006- 2012

\begin{tabular}{|c|c|c|c|c|c|c|c|}
\hline Public expenses & 2006 & 2007 & 2008 & 2009 & 2010 & 2011 & 2012 \\
\hline $\begin{array}{c}\text { Total (in thousands PLN) } \\
\text { including: }\end{array}$ & 808,560 & 891,541 & 896,802 & 846,782 & 997,678 & 1,049091 & 1,161884 \\
\hline State budget & 608,920 & 612,901 & 702,185 & 630,422 & 775,118 & 796,485 & 908,721 \\
\hline National Health Fund & 147,760 & 220,221 & 126,611 & 132,349 & 140,045 & 170,816 & 175,841 \\
\hline Local government units & 51,880 & 58,420 & 68,006 & 84,011 & 82,515 & 81,790 & 77,322 \\
\hline $\begin{array}{c}\text { Share of budget expenses in } \\
\text { total health care budget } \\
\text { expenses (in \%) }\end{array}$ & 15.8 & 11.0 & 10.5 & 9.3 & 11.3 & 10.5 & 12.1 \\
\hline $\begin{array}{c}\text { Share of NFZ expenses in } \\
\text { total NFZ health care } \\
\text { expenses (in \%) }\end{array}$ & 0.28 & 0.40 & 0.19 & 0.22 & 0.23 & 0.27 & 0.30 \\
\hline $\begin{array}{c}\text { Share of expenses of local } \\
\text { government units in total } \\
\text { health care expenses of local } \\
\text { government units (in \%) }\end{array}$ & 1.7 & 1.9 & 1.8 & 2.0 & 2.0 & 2.0 & 2.2 \\
\hline
\end{tabular}
* Duet to considerable discrepancies in the commonly used terminology, the "health policy programs" term has been adopted in the study for uniformization
purposes

Source: own work on the basis of reports of the state budget execution, NFZ reports and reports on the execution of local government budgets. 
An overview of preventive health programs, and mostly sources and the level of their financing, shows a lot of irregularities which are against contemporary principles of rational use of public funds. The diagnosed problems have a financial aspect (Poland spends nearly $60 \%$ less on disease prevention than other EU countries. In Netherlands, France and Germany over eight, six and five times more funds are spend on this purpose, respectively). And these funds are also use for the creation and implementation of preventive health programs [10]. In an analysis of the situation of disease prevention, it should be emphasized that the possibilities of influencing the population's health are not sufficiently used. There is no mechanism coordinating their implementation, tasks are performed by a lot of entities and a lot of them are performed only partially. The "continuous reform" status results in a lack of stable organizational and financial solutions, has not favoured precise determination of the place of preventive health programs in the state's health policy.

\section{Cancer Prevention: Examples of Good Practice}

Differences between European countries listed in previous part of this article pertaining to expenditures on disease prevention show that the only reasonable method of making comparisons in the area of its financing is an analysis of specific actions (specific program) and the method of their implementations in various countries. And the fact whether health programs are considered a part of health care, social care or community services and whether it is the local administration or central authorities that are responsible for them is probably a factor of little importance for the health effects achieved as a result of the program implementation.

The choice of cancer prevention as the object of the study can be justified. Firstly, cancer is one of the main causes of all deaths in the population. It is now the third (12.62\%) cause of deaths in the world after circulatory system diseases $(29.03 \%)$ and contagious diseases (16.19\%). According to estimates of the World Health Organization (WHO), in 2008 12.4 million of new cases of cancer were diagnosed and 7.6 million deaths were recorded in the world and approx. 28 million people lived with active cancer. According to WHO, the number of new cases may go up to 27 million a year, the number of deaths will stay at the level of 17 million and the number of persons living in a 5-year period following the cancer diagnosis will amount to 75 million [11].

Another reason for selecting actions in the area of limiting cancer is the fact that in many countries these actions usually have the form of organized strategies and programs monitored both in terms of medical, epidemiological and economic effectiveness and efficiency. The importance of prevention in fighting cancer cannot be denied.

Comparative studies pertaining to financing cancer fighting programs usually include both treatment and prevention. At present, the isolation of only cancer prevention is a difficult task. This result from the quality of information collected in individual countries within a varying scope. An analysis of national cancer fighting plans in Europe is an example here [12]. Some countries (Belgium, Anglia, Estonia, France, Lithuania, Netherlands, Northern Ireland, Norway) provide data on financing, planning and implementing the cancer fighting strategy at the macro level. But among these countries, only Belgium, England and France estimated the total budget intended for the implementation of specific actions. Thus, EUR 380 million were intended for this purpose in the years 2008-2010. In treatment, GBP 70 million is used for cancer treatment a year in England, while in France EUR 640 million was used in 2007. However, the majority of countries do not specify the amount of the budget or funds which will be used for specific elements and the reasons for such allocation.

A general lack of funds for cancer fighting plans, including preventive actions raises concern in many countries, implying that a large part of these plans will be deprived of pillars allowing for the achievement of assumed goals which are very ambitious in some cases. The current financial climate makes this problem even more serious. All actions must specify the sources of financing, the amount of funds necessary to implement preventive programs and to satisfy the ongoing and future health-related needs connected with cancer treatment and areas where these funds will be allocated.

Due to difficulties in performing broad financial analyses concerning a large number of countries and a large number of actions connected with cancer treatment and prevention, the presentation of actions taken in selected countries seems to be more reliable. The presentation of Nordic countries as examples of good practices in the implementation of cancer prevention is not an accidental choice. Finland's, Sweden's Denmark's and Iceland's achievements in prevention have been commonly known for many years. These countries attach a lot of importance to cancer prevention, especially in the area of screening tests for breast and cervical cancer.

While making a decision on the introduction of preventive tests (mostly screening tests), a lot of factors must be considered. Already in 1968, criteria were formulated according to which screening should be conducted, these include [13]:

1. An important health and social problem;

2. Well-known and understood natural history of the disease;

3. Possibility of curing the disease at an early stage;

4. Much better results at an early stage;

5. Possibility of curing a detected disease;

6. The existence of appropriate tests allowing for detecting the disease;

7. These tests must be acceptable;

8. Mass quality and repeatability of screening must be ensured;

9. Benefits are greater than the risk;

10. Population costs of tests are not higher than treatment costs.

Screening programs are used in all Scandinavian countries 
(Table 2).

Table 2. Policy of screening tests in individual Nordic countries.

\begin{tabular}{|c|l|}
\hline \multicolumn{2}{|c|}{ Breast cancer } \\
\hline Finland & $\begin{array}{l}\text { Women aged 50-59 (since 2004 the target group has } \\
\text { been extended to include the 60-69 age group) every } 2 \\
\text { years }\end{array}$ \\
\hline Norway & Women aged 50-69 every 2 years \\
\hline Sweden & $\begin{array}{l}\text { Women aged 40-74, every 18 months under 55 years of } \\
\text { age, every two years for the 55-74 age group }\end{array}$ \\
\hline Denmark & Women aged 50-69 every 2 years \\
\hline Iceland & Women aged 40-69 every 2 years \\
\hline $\begin{array}{c}\text { Faroe } \\
\text { Islands }\end{array}$ & No data available \\
\hline \multirow{2}{*}{ Cervical cancer } \\
\hline Finland & Women aged 30-60 every 5 years \\
\hline Norway & Women aged 25-69 every 3 years \\
\hline Sweden & $\begin{array}{l}\text { Women aged 23-50 every } 3 \text { years, aged 51-60 every 5 } \\
\text { years }\end{array}$ \\
\hline Denmark & $\begin{array}{l}\text { Women aged 23-50 every } 3 \text { years, aged 51-65 every } 5 \\
\text { years }\end{array}$ \\
\hline Iceland & $\begin{array}{l}\text { Women aged 20-39 every 2 years, aged 40-69 every 2-4 } \\
\text { years. Before 2009: women aged 20-69 every 2 years }\end{array}$ \\
\hline $\begin{array}{l}\text { Faroe } \\
\text { Islands }\end{array}$ & Women aged 25-69 every 3 years \\
\hline
\end{tabular}

Source: own work on the basis of Costs of cancer in the Nordic countries $A$ comparative study of health care costs and public income loss compensation payments related to cancer in the Nordic countries in 2007, SINTEF Technology and Society Health Services Research, 2011,

There is some differentiation among Scandinavian countries in the area of the range of all domestic screening programs. This mostly applies to the frequency of tests and age groups included in such tests. As it can be seen in Table 2, Finland, Norway and Iceland offer screening tests every two years for breast cancer, while Sweden provides such tests every 18 months for the youngest age group and every two years for the oldest group. The age of the target group is another factor which causes differences. In Iceland and Sweden, women after the age of 49 are invited to take part in early breast cancer detection tests, while in the other Scandinavian countries this program includes women over the age of 50. Differences between the countries also include the duration of such a program. Apart from Sweden, the program includes women until the age of 69, while in Sweden - until the age of 74. Similar differences occur between screening programs for cervical cancer functioning in individual Scandinavian countries. Iceland begins to test the youngest women. Finland is on the other end of the scale. This fact can be also easily accounted for by policies adopted by these countries in the area of preventive tests. In the case of cervical cancer, Finland begins to test older women than the other countries and, at the same time, the upper age limit is lower than in the majority of them. In addition, the frequency of tests is lower than in the other countries.

The presented comparison of screening programs functioning in Nordic countries shows how differentiated the adopted solutions can be. However, in the context of considerations undertaken in this article, the most important issue is the fact that costs of screening tests are calculated in these countries (Graph 5).

Due to the differences in the methods of calculating unit costs, average unit costs calculated on the basis of national estimates were used to calculate costs of screening tests in all countries. These estimates include direct health care costs connected with the performance of screening tests which include:

- the mammography cost for breast cancer = (non-refundable payment + constant unit price* standard mammography weight)*100/40 (with the assumption of $40 \%$ cost coverage) + check-up cost (added to $3.4 \%$ of screening test) = mammography cost + ultrasound cost + biopsy cost;

- for cervical cancer, the cost of cytological tests $=(\mathrm{GP}$ appointment + smear collection procedure + materials + path/processing at the laboratory) + HPV test cost (added to $1.6 \%$ of tests $)=($ rate for a patient treated outside the hospital plus patient financing per visit).

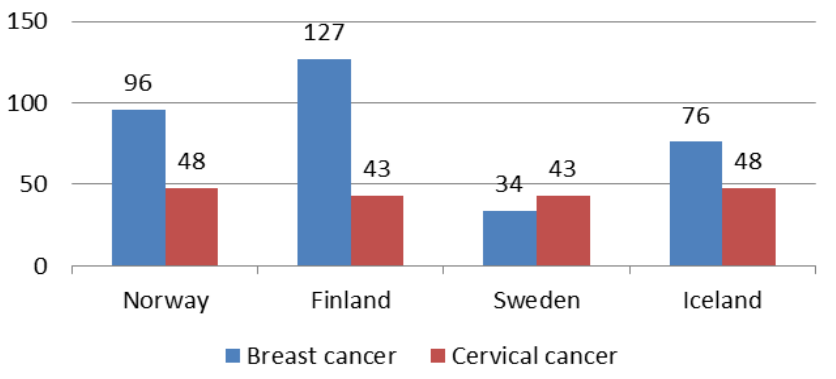

Source: own work on the basis of Costs of cancer in the Nordic countries A comparative study of health care costs..., op.cit.

Graph 5. Per capita cost of screening tests (in Euros)

Costs of screening tests are very different in individual countries. For breast cancer, the highest costs of screening programs are incurred in Sweden, Iceland ranks second. For cervical cancer, Iceland spends the most money and Norway ranks second. If we compare the national estimated costs of both programs, we will notice that the estimated costs of early breast cancer detection programs in Finland are much higher than in the case of cervical cancer. The difference in costs between both programs is lower in Iceland. These differences in costs observed between the countries are only a function of the estimated number of tests per person as the same unit cost of the test was established for all the countries, taking in account direct costs of health care connected with the test (EUR 94 for breast cancer and EUR 45 for cervical cancer).

Also in Poland programs for early detection of breast cancer and cervical cancer are implemented. They are a part of the "National Program for Fighting Cancer" [14]. The average cost of one cytological tests in 2010 was PLN 66.84 (it is approx. EUR 16), and the mammography costs is PLN 58.42 (approx. EUR 14). Due to lack of detailed information on both programs, the presented estimates are based on two values: the total financial expenditures used towards the implementation of the programs and the number of mammography examinations and cytological tests. These 
estimated calculations allow for showing low costs of both programs.

Participation in programs is the basic problem in Poland. Very few women report for mammography examinations - it was $37 \%$ in $2010.41 \%$ women reported for cytological tests. According to EU experts' recommendations, the recommended numbers of patients reporting for these tests should be above $75 \%$, the acceptable level is $70 \%$.

Survival rates are worth having a look at (Table 3 ) as they allow for evaluating the policy in the area of fighting cancer, thus, not only the treatment but also the effectiveness of preventive actions.

Table 3. The index of the relative 5-year survival rates standardized for the age in the years 2000-2002

\begin{tabular}{|c|c|c|c|}
\hline $\begin{array}{c}\text { Groups of } \\
\text { countries }\end{array}$ & Countries & $\begin{array}{c}\text { All malignant } \\
\text { tumours - men }\end{array}$ & $\begin{array}{c}\text { All malignant } \\
\text { tumours - } \\
\text { women }\end{array}$ \\
\hline $\begin{array}{c}\text { Three countries } \\
\text { with the greatest } \\
\text { achievements }\end{array}$ & Sweden & 60.3 & 61.7 \\
& Fceland & 57.7 & 61.8 \\
Finland & Great & $(40.2-48.1)$ & $(48.0-54.1)$ \\
Three largest & Britain & 50.0 & 58.8 \\
countries & Germany & 49.8 & 59.7 \\
\hline $\begin{array}{c}\text { Countries in the } \\
\text { most difficult } \\
\text { situation }\end{array}$ & Poland & 38.8 & 48.3 \\
\hline
\end{tabular}

Source: N. Wilking, B. Jonsson, D. Hogberg: Comparator Report of Patient Access to Cancer Drugs in Europe. Karolinska Institute. Stockholm 2009, p. 11

Countries selected as an example of good practices are among countries with the greatest achievements in the effectiveness of fighting cancer, while Poland is among countries in the most difficult situation. Of course, other factors which influence the survival rates, such as the level of economic development of the country, however, it should constitute even greater motivation for decision makers in the health care system to take more action in the area of these factors which can be influenced and preventive actions belong to this group of activities.

\section{Conclusions}

A considerable increase in health care expenses has been observed over the past decade. In the majority of them, these expenses are a considerable burden for the public finance sector. Keeping the trend of increasing health expenses in relation to the GDP will constitute a serious challenge for public finance. In this context, it will be very important to increase effectiveness of the use of funds currently available in the public health care system. Disease prevention is among potential actions which will allow for implementing this objective. An increase in the effectiveness and quality of health care is favoured by the organization of diagnosing and treatment processes targeted at quick detection of diseases and their treatment at this level of the system, when it brings expected health results with the lowest expenditures.
However, the necessity to increase preventive actions shown in plans and strategies concerning health care is often declarative as it is not reflected by appropriate financing of preventive health programs.

Demographic changes which are currently taking place, mostly society's ageing, significantly increase the costs and threaten the balance of the health care system not only in Poland but also in all other EU countries. Considering also problems connected with epidemiology: high mortality rates due to circulatory system diseases, growing mortality rates due to cancer, growing incidence of chronic diseases, it should be expected that health care in the years to come will require significant reorganization in the area of treatment, rehabilitation and social care of the ageing population and mostly in the area of disease prevention. With limited funds, this should lead to a change in the expense structure of the health care system. Hence, the necessity to redefine priorities in the health care system is fully justified.

\section{REFERENCES}

[1] Sokołowska M., Socjologia medycyny, PZWL, Warszawa 1986.

[2] Słońska Z. Promocja zdrowia - zarys problematyki, Promocja Zdrowia. Nauki Społeczne i Medycyna, Issue $1-2 / 1994$.

[3] Nettleton S., The sociology of health and illness, Polity Press, Oxford 2003

[4] Bloom D., Canning D., Sevilla, J., The effect of health on economic growth: Theory and evidence, NBER Working Paper 8587, Cambridge: National Bureau of Economic Research (www.nber.org/papers/w8587), 2001.

[5] Suhrcke M., McKee M., Sauto Arce R., Tsolova S. , Mortensen J. The contribution of health to the economy in the European Union, 23 August 2005 EUROPEAN COMMISSION, Bruksela 2005.

[6] OECD (2011), Health at a Glance 2011: OECD Indicators, OECD Publishing.

http://dx.doi.org/10.1787/health_glance-2011-en

[7] Report on Health Systems Council of The European Union, 29 November 201016940/10.

[8] The 2012 Ageing Report .Economic and budgetary projections for the 27 EU Member States (2010-2060), European Economy 2|2012.

[9] Nawrolska I. Healthcare system in Poland- 20 years of transformation, in: 20 years after-finance in Poland 1989-2009, T. Lubińska (ed.) Wydawnictwo Economicus, Szczecin 2009.

[10] Nawrolska I. ,Finansowanie profilaktycznych programów zdrowotnych ,Difin, Warszawa 2013.

[11] Boyle B. , Levin B., World Cancer Report 2008. Lyon 2008, WHO. 
[12] Wilson J.M.G, Junger G., Principles and Practice of Screening for Disease, WHO 1968.

[13] Atun R., Ogawa T., Martin-Moreno J.M., Analysis of National Cancer Control Programmes in Europe, Imperial
College London Business School, London 2011

[14] Ustawa z dnia 1 lipca 2005 r. o ustanowieniu programu wieloletniego „Narodowego Programu Zwalczania Chorób Nowotworowych" (Dz. U. nr 143, poz. 1200 z 2005 r.) 